\title{
Correlation Studies and Predictive Models of Kharif Greengram based on Agroclimatic Indices
}

\author{
Mangshatabam Annie $^{1^{*}}$, Bondita Goswami $^{1}$, Pranjal Dutta ${ }^{1}$, \\ Ramani Kanta Thakuria ${ }^{2}$ and Kakali Konwar ${ }^{2}$ \\ ${ }^{1}$ Department of Agrometeorology, Assam Agricultural University, \\ Jorhat-785013, Assam, India \\ ${ }^{2}$ Department of Agronomy, Assam Agricultural University, Jorhat-785013, Assam, India
}

*Corresponding author

\section{A B S T R A C T}

\section{Keywords}

Greengram,

Correlation, ADRF,

ABSH, AGDD

Article Info

Accepted:

07 October 2019

Available Online:

10 November 2019
A detailed study on greengram was carried out with treatments comprised of three different micro-climatic environments i.e. MR-I: $\left(25^{\text {th }} \mathrm{Aug}\right)$, MR-II: $\left(10^{\text {th }} \mathrm{Sep}\right)$ and MR-III: $\left(25^{\text {th }}\right.$ Sep) with three varieties viz., SG-16, SG-20 and IPBM-02-3. The results obtained from the experiment revealed that total accumulated agroclimatic indices showed a gradual decrease in the three successive micro-climatic regimes irrespective of varieties. The correlation study was carried out between weather variables prevailed during vegetative to maturity stages of different varieties under different microclimatic regimes. Most of the agro-climatic indices and meteorological parameters yielded higher correlation coefficients with final yield irrespective of varieties and microclimatic regimes for all growth stages. Highest correlation coefficient among accumulated indices was found in accumulated rainfall, ADRF (0.952) corresponding to vegetative stages. While the lowest correlation coefficient was obtained in accumulated bright sunshine hours, ABSH (-0.914) corresponding to reproductive stages. A few predictive models involving both accumulated indices and mean parameters were also developed combined over both varieties and microclimatic regimes corresponding to different crop growth stages. The most efficient model was found for the accumulated rainfall (ADRF), accumulated bright sunshine hours (ABSH) and accumulated growing degree days (AGDD) corresponding to vegetative, reproductive and maturity stage respectively. Lower per cent variations (PCV) were indicative of the fact that the predicted models are very effective under agro-climatic conditions of Jorhat.

\section{Introduction}

Greengram is the third most important pulse crop after chickpea and pigeon pea in India. It is native of India and central Asia and grown in these regions since prehistoric times. In
Assam it is cultivated in 0.12 lakh ha producing about 0.06 lakh tones with a productivity of $5.56 \mathrm{q} / \mathrm{ha}$ (Anonymous, 201213). It is a short duration crop and has been important component of Indian agriculture as it has wider adaptability and low input 
requirements and have the ability to fix the nitrogen in symbiotic association with rhizobia (58-109 $\mathrm{kg} / \mathrm{ha})$, which not only enables it to meet its own nitrogen requirement but also benefits the succeeding crops (Singh and Singh, 2011). Mungbean provides $33-37 \mathrm{~kg} / \mathrm{ha}$ of nitrogen $(\mathrm{N})$ to the soil after harvest and thus helps in saving of about 25 per cent nitrogen for the succeeding crop enabling the land to restore fertility (Sekhon et al., 2007). Inter cropping or mixed cropping of mungbean with cash crops enriches the soil and breaks the soil fatigue caused by cereal-cereal rotations. The weather parameters play an important role in deciding the success or failure of the crop, because they strongly influence the physiological expression and genetic potential of the crop. It is well known that yield from any given crop or variety depends on the availability of certain optimum rainfall, solar radiation, temperature, relative humidity, heat units etc. during different stages of crop growth. Among different management factors, sowing time plays a key role in obtaining higher yield. The optimum time is mainly dependent on prevailing agro-climatic conditions of an area besides the variety grown. Sowing during the optimum period, therefore, ensures better harmony between the plant and weather which ultimately results in higher crop yields (Venkatshwarulu and Soundararajan, 1991). The present study aimed to evaluate the correlation coefficients in order to assess the impact of different weather indices prevailed during the crop life for the various phenological stages and to develop some predictive model for different microclimatic regimes under the agroclimatic conditions of Jorhat.

\section{Materials and Methods}

The experiment was conducted at ICR farm of AAU, Jorhat district of Assam (latitude of $26^{\circ} 47^{\prime} \mathrm{N}$ and longitude $94^{\circ} 12^{\prime} \mathrm{E}$ ) during kharif season of 2018. Jorhat is located in a subtropical belt with hot and humid summers and cold and dry winters. The mean annual rainfall is $1900 \mathrm{~mm}$, of which 62.6 per cent is received during south-west monsoon from June to September. During post monsoon (OctoberDecember), pre-monsoon (March-May) and winter season (January- February), the station receives 7.5, 26.2 and 3.7 per cent of annual rainfall, respectively. Monthly morning relative humidity of the station always remains above 85 percent, whereas monthly evening relative humidity varies from 61 to 76 per cent throughout the year. The monthly average maximum and minimum temperatures vary from 22.6 to $32.7^{\circ} \mathrm{C}$ and 9.7 to $25.2^{\circ} \mathrm{C}$ respectively. The soil texture of the experimental site was sandy loam with medium organic carbon content, low in nitrogen and phosphorus and medium in potassium contents. The field experiment was laid out in Split Plot Design with four replications. There were nine treatment comprising of three varieties in main plot viz (V1: SG-16, V2: SG-20 and V3: IPBM-02-3). Sowing dates (3nos) were assigned in sub plot viz. MR-1 $\left(25^{\text {th }}\right.$ Aug i.e. $\left.34^{\text {th }} \mathrm{MW}\right)$, MR-II $\left(10^{\text {th }}\right.$ Sep i.e. $\left.37^{\text {th }} \mathrm{MW}\right)$ and MR-III $\left(25^{\text {th }}\right.$ Sep i.e. $\left.39^{\text {th }} \mathrm{MW}\right)$. The crop was sown with spacing $30 \times 10 \mathrm{~cm}$. The periodical observations on growth characters, post harvest observation and yield contributing characters of green gram were recorded to assess the treatments effects. Daily data of weather variables, viz. maximum and minimum temperature, morning and evening relative humidity, Rainfall, pan evaporation and bright sunshine hours (BSSH) for the entire crop growing season was collected from the meteorological observatory of the Department of Agrometeorology, AAU, Jorhat-13. The data were statistically analyzed and correlation between green gram yield and different weather parameters was carried out (Gomez and Gomez, 1984). Computer software SPSS (version 20) was used. Predictive models 
(regression models) were developed involving seed yield and selected accumulated agroclimatic indices corresponding to different crop growth stages.

\section{Results and Discussion}

The data on seed yield as affected by different growing environments are presented in the Table 1. The result on seed yield revealed that sowing done on $34^{\text {th }}$ MW recorded significantly higher seed yield $(787 \mathrm{~kg} / \mathrm{ha})$ as compared to sowing done on $37^{\text {th }} \mathrm{MW}$ and $39^{\text {th }}$ MW. Delay in sowing times negatively influenced its yield therefore, early sowing produced higher yield than late sowing. Similar result was also reported by Ali et al., (2014) and Jiotode et al., (2017) who obtained higher values of yield attributing parameters in early sown greengram than in late sown crop due to favourable growing conditions which ultimately resulted in higher yield in early sown greengram. Data also revealed that variety SG-20 produced significantly higher yield i.e. $701 \mathrm{~kg} / \mathrm{ha}$ as compared to variety SG-16 and IPBM-02-3.

\section{Correlation analysis}

The correlation studies were undertaken to assess the impact of different weather indices prevailed during the crop life for the various phenological stages which were important in utilizing the weather resources for the synthesis of yield. Correlation was worked out between yield and different accumulated agroclimatic indices viz. AMXT, AMNT, AMET, ARHI, ARHII, AMRH, ADRF, APNE, ABSH, AGDD, AHTU and APTU. The results are presented in Table 2. At vegetative stages ADRF, APNE, AGDD and APTU were found to be positively significant correlations with respect to yield at $1 \%$ level of significance. However ARHI, ARHII, AMRH, ABSH and AHTU yielded negative correlation with seed yield. At reproductive stage, AMNT, AGDD and APNE showed significant positive correlations with seed yield at $1 \%$ level of significance. Negative significant correlations at $1 \%$ and $5 \%$ level of significance were found in $\mathrm{ABSH}$ and $\mathrm{AHTU}$ respectively. However, ARHI, ARHII, AMRH and APNE were negatively correlated and were non-significant. At maturity stage, significant positive correlations were found in AMNT, AGDD, APTU and AHTU at 1\% level of significance. However, a negative significant relationship at 5\% level of significance was observed in ARHII, AMRH and $\mathrm{ABSH}$.

\section{Predictive models}

Predictive models were developed using accumulated agroclimatic indices corresponding to different crop growth stages and are presented in Table 3 and also graphically depicted in Figure 1. From Table 3 , it is evident that among the accumulated agroclimatic indices, the best model was found for ADRF, ABSH and AGDD corresponding to the vegetative, reproductive and maturity phase with higher value of coefficient of determination of $0.906,0.834$ and 0.880 respectively. Using some selected predictive models, yields were estimated for different crop phenological stages in green gram. Then the percent variation (PCV) between the predictive and actual yields was worked out for all the 9 different treatment combinations and the results are presented in Table 4. From the Table 4, it was observed that the regression model developed for different phenophases showed accurate and useful prediction because its error percentage were very less $(<10 \%)$ irrespective of crop phonological stages. Such low per cent variation $(\mathrm{PCV})$ indicates that the predictive yields are very close to their corresponding actual yields. 
Table.1 Seed yield of greengram during kharif, 2018

\begin{tabular}{|c|c|}
\hline Treatment & Seed yield (kg/ha) \\
\hline \multicolumn{2}{|c|}{ Variety } \\
\hline$V_{1}-S G-16$ & 648 \\
\hline$V_{2}-S G-20$ & 701 \\
\hline$V_{3}-$ IPBM-02-3 & 630 \\
\hline Mean & 660 \\
\hline SE(V) & 9.63 \\
\hline CD at $5 \%$ & 24.01 \\
\hline \multicolumn{2}{|c|}{ Micro-climatic regimes } \\
\hline MR-I(34 ${ }^{\text {th }}$ MW $)$ & 787 \\
\hline MR-II $\left(37^{\text {th }}\right.$ MW $)$ & 655 \\
\hline MR-III(39 $\left.{ }^{\text {th }} M W\right)$ & 537 \\
\hline Mean & 660 \\
\hline SE(MR) & 12 \\
\hline CD at $5 \%$ & 25.41 \\
\hline \multicolumn{2}{|l|}{$\mathbf{V} \times \mathbf{M R}$} \\
\hline CD at $5 \%(\mathrm{~V} \times \mathrm{MR})$ & NS \\
\hline $\mathrm{CD}$ at $5 \%(\mathrm{MR} \times \mathrm{V})$ & NS \\
\hline
\end{tabular}

Table.2 Correlation between seed yield and phasic mean meteorological parameter in greengram, during kharif, 2018

\begin{tabular}{|c|c|c|c|c|c|c|c|c|c|c|c|c|}
\hline *Phase & $\begin{array}{c}\mathbf{A M X} \\
\mathbf{T} \\
\left({ }^{\circ} \mathbf{C}\right)\end{array}$ & $\begin{array}{c}\text { AMNT } \\
\left({ }^{\circ} \mathbf{C}\right)\end{array}$ & $\begin{array}{c}\text { AME } \\
\text { T } \\
\left({ }^{\circ} \mathbf{C}\right)\end{array}$ & $\begin{array}{c}\text { ARHI } \\
(\%)\end{array}$ & $\begin{array}{c}\text { ARHI } \\
\text { I (\%) }\end{array}$ & $\begin{array}{c}\text { AMR } \\
\text { H (\%) }\end{array}$ & $\begin{array}{c}\text { ADR } \\
\text { F } \\
(\mathbf{m m})\end{array}$ & $\begin{array}{c}\text { APNE } \\
(\mathbf{m m} / \\
\text { day })\end{array}$ & $\begin{array}{c}\text { ABSH } \\
\text { (hr) }\end{array}$ & $\begin{array}{c}\text { AGDD } \\
\left({ }^{\circ} \mathbf{C}\right)\end{array}$ & $\begin{array}{c}\text { APTU } \\
\left(\begin{array}{c}{ }^{\circ} \mathrm{C} \text { days } \\
\text { hr })\end{array}\right.\end{array}$ & $\begin{array}{c}\text { AHTU } \\
\left({ }^{\circ} \mathrm{C}\right. \\
\text { days } \\
\text { hr })\end{array}$ \\
\hline Vegetative & 0.408 & & $74^{*}$ & $3 * *$ & & & $0.952 * *$ & & & & & -0.648 \\
\hline $\begin{array}{c}\text { Re- } \\
\text { productive }\end{array}$ & 0.011 & $0.817 * *$ & 0.512 & -0.294 & -0.407 & -0.019 & 0.134 & -0.220 & $-0.914 * *$ & $0.823 * *$ & $0.849 * *$ & $-0.695^{*}$ \\
\hline Maturity & -0.115 & $922 * *$ & $0.797 *$ & $-0.815^{* *}$ & $-0.736^{*}$ & $-0.797^{*}$ & 0.099 & 0.590 & $-0.767 *$ & $0.938 * *$ & $0.928^{*}$ & $0.821 * *$ \\
\hline
\end{tabular}

*and**significant at 5 and 1 percent levels, respectively

Table.3 Predictive models involving seed yield and accumulated agro-climatic indices in green gram during kharif, 2018 (Combined over varieties and micro-climatic regimes)

\begin{tabular}{|c|c|c|c|}
\hline Phenological events & Models & F & $\mathbf{R}^{\mathbf{2}}$ \\
\hline Vegetative & $\mathrm{Y}=502.77+0.703 \mathrm{ADRF}$ & $67.92 * *$ & 0.906 \\
\hline Reproductive & $\mathrm{Y}=1168.75-5.24 \mathrm{ABSH}$ & $35.39 * *$ & 0.834 \\
\hline Maturity & $\mathrm{Y}=3.71 \mathrm{AGDD}-150.37$ & $51.48 * *$ & 0.880 \\
\hline
\end{tabular}

ADRF: Accumulated rainfall, ABSH: Accumulated bright sunshine hour, AGDD: Accumulated growing degree days 
Table.4 Percent variations between predicted and actual yields in green gram during kharif, 2018 (Accumulated agroclimatic indices)

\begin{tabular}{|c|c|c|c|c|}
\hline Predictive Model & \multicolumn{4}{|c|}{$Y=502.77+0.703$ ADRF $\left(R^{2}=0.906\right)$} \\
\hline Phenophase & Treatment & $\mathbf{Y}$ & $\mathbf{Y}^{\wedge}$ & PCV \\
\hline \multirow{9}{*}{ Vegetative } & $\mathrm{V}_{1} \mathrm{D}_{1}$ & 785 & 763 & -2.86 \\
\hline & $\mathrm{V}_{1} \mathrm{D}_{2}$ & 635 & 653 & 2.76 \\
\hline & $\mathrm{V}_{1} \mathrm{D}_{3}$ & 524 & 538 & 2.56 \\
\hline & $\mathrm{V}_{2} \mathrm{D}_{1}$ & 815 & 796 & -2.48 \\
\hline & $\mathrm{V}_{2} \mathrm{D}_{2}$ & 707 & 654 & -8.09 \\
\hline & $\mathrm{V}_{2} \mathrm{D}_{3}$ & 580 & 538 & -7.74 \\
\hline & $\mathrm{V}_{3} \mathrm{D}_{1}$ & 761 & 798 & 4.68 \\
\hline & $\mathrm{V}_{3} \mathrm{D}_{2}$ & 621 & 657 & 5.55 \\
\hline & $\mathrm{V}_{3} \mathrm{D}_{3}$ & 508 & 538 & 5.67 \\
\hline Predictive Model & \multicolumn{4}{|c|}{$Y=1168.75-5.24$ ABSH $\left(R^{2}=0.834\right)$} \\
\hline Phenophase & Treatment & $\mathbf{Y}$ & $\mathbf{Y}^{\wedge}$ & PCV \\
\hline \multirow{9}{*}{ Reproductive } & $\mathrm{V}_{1} \mathrm{D}_{1}$ & 785 & 786 & 0.11 \\
\hline & $\mathrm{V}_{1} \mathrm{D}_{2}$ & 635 & 615 & -3.38 \\
\hline & $\mathrm{V}_{1} \mathrm{D}_{3}$ & 524 & 496 & -5.78 \\
\hline & $\mathrm{V}_{2} \mathrm{D}_{1}$ & 815 & 793 & -2.78 \\
\hline & $\mathrm{V}_{2} \mathrm{D}_{2}$ & 707 & 660 & -7.10 \\
\hline & $\mathrm{V}_{2} \mathrm{D}_{3}$ & 580 & 597 & 2.96 \\
\hline & $\mathrm{V}_{3} \mathrm{D}_{1}$ & 761 & 778 & 2.18 \\
\hline & $\mathrm{V}_{3} \mathrm{D}_{2}$ & 621 & 643 & 3.50 \\
\hline & $\mathrm{V}_{3} \mathrm{D}_{3}$ & 508 & 538 & 5.64 \\
\hline Predictive Model & \multicolumn{4}{|c|}{$Y=3.71$ AGDD $-150.37\left(R^{2}=0.880\right)$} \\
\hline Phenophase & Treatment & $\mathbf{Y}$ & $\mathbf{Y}^{\wedge}$ & PCV \\
\hline \multirow{9}{*}{ Maturity } & $\mathrm{V}_{1} \mathrm{D}_{1}$ & 785 & 766 & -2.51 \\
\hline & $\mathrm{V}_{1} \mathrm{D}_{2}$ & 635 & 640 & 0.79 \\
\hline & $\mathrm{V}_{1} \mathrm{D}_{3}$ & 524 & 508 & -3.13 \\
\hline & $\mathrm{V}_{2} \mathrm{D}_{1}$ & 815 & 764 & -6.77 \\
\hline & $\mathrm{V}_{2} \mathrm{D}_{2}$ & 707 & 661 & -6.95 \\
\hline & $\mathrm{V}_{2} \mathrm{D}_{3}$ & 580 & 568 & -2.11 \\
\hline & $\mathrm{V}_{3} \mathrm{D}_{1}$ & 761 & 810 & 6.07 \\
\hline & $\mathrm{V}_{3} \mathrm{D}_{2}$ & 621 & 676 & 8.09 \\
\hline & $\mathrm{V}_{3} \mathrm{D}_{3}$ & 508 & 543 & 6.61 \\
\hline
\end{tabular}


Fig.1 Predictive models involving seed yield and accumulated agroclimatic indices in greengram during kharif, 2018 for Vegetative, Reproductive and Maturity stages.
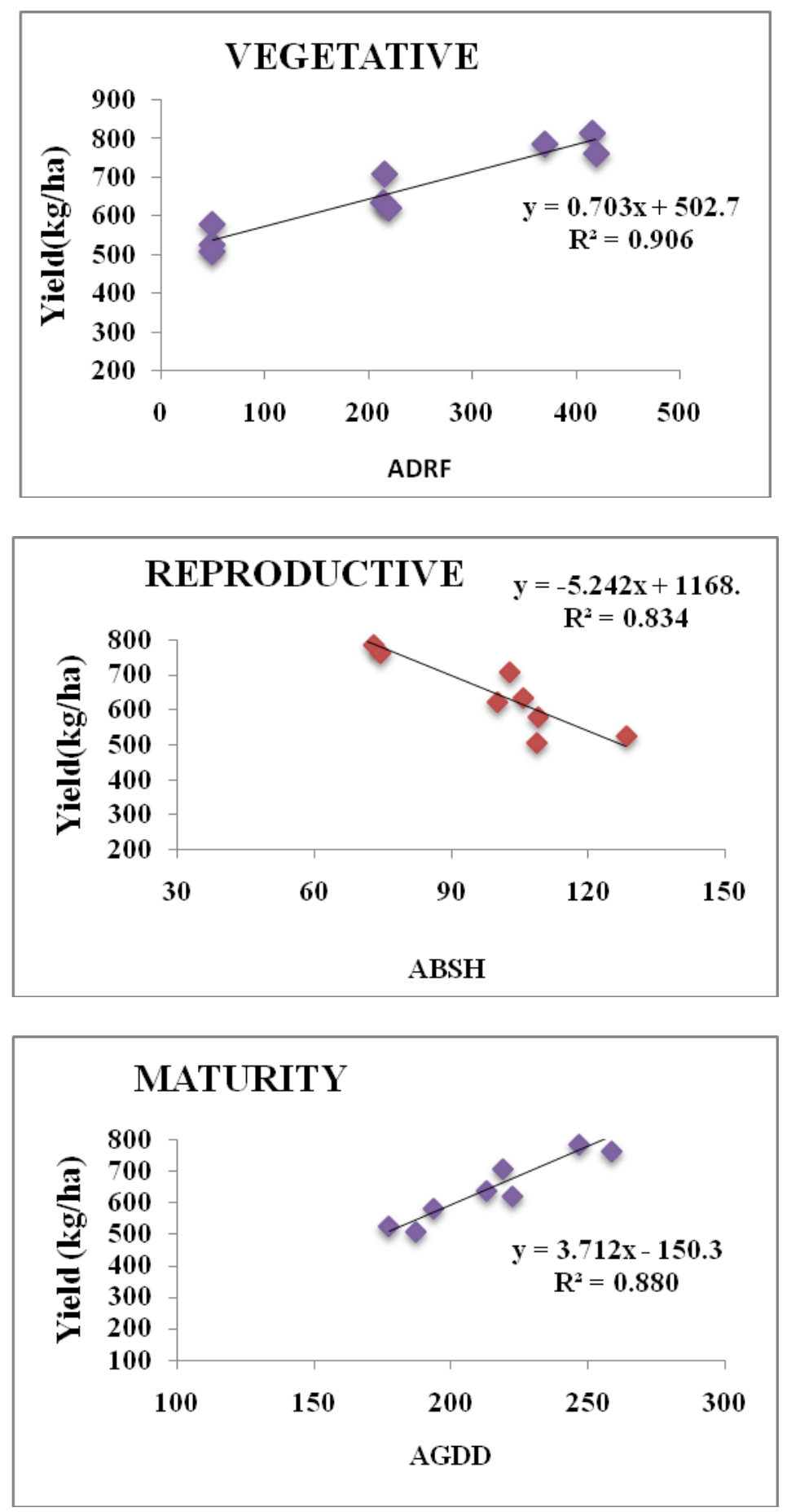
Therefore, it can be inferred that such predictive models can successfully be used for predicting seed yield of green gram well ahead of crop maturity under the prevailing agroclimatic conditions of Jorhat.

Result showed that among different sowing dates in green gram, sowing done under MR-I was found optimum for achieving higher seed yield. Among the correlations workout with various agrometeorological indices, ADRF showed the highest correlation coefficient. Predictive models which were develop showed very low $(<10)$ per cent variations between predicted and actual yields which is indicative of the efficacy of the models.

\section{References}

Ali, S., Khaliq, T., Ahmad, A., Muzammal, R., Hussain, S., Rehman, K. and Parvez, M.V. (2014). Genotypic variation in mungbean yield and its attributes in response to different sowing times. Res. J. Agric. Environ. Management, 3(5): 255-258.

Anonymous (2013). Economic Survey of
Assam, 2011-12.

Gomez, K.A. and Gomez, A.A. (1984). Statistical procedures for agricultural research. $2^{\text {nd }}$ ed., pp. 680 .

Jiotode, D.J., Sonune, D.G., Mohod, A.R., Parlawar, N.D. and Khawale, V.S. (2017). Studies on effect of weather parameters on kharif green gram (Vigna radiata L.) varieties under different sowing dates. J. soils and crops, 27(2): 185-191.

Sekhon, H.S., Bains, T.S., Kooner, B.S. and Sharma, P. (2007). Grow summer mungbean for improving crop sustainability, farm income and malnutrition. Acta Horticulturae, 752: 459-464.

Singh, D.P and Singh, B.B. (2011). Breeding for tolerance to abiotic stresses in Mungbean. J. food legumes, 24(2): 8390.

Venkatshwarulu, M.S. and Soundararajan, M.S. (1991). Influence of season on growth and yield attributes of black gram. Indian J. Agronomy, 36: 119123.

\section{How to cite this article:}

Mangshatabam Annie, Bondita Goswami, Pranjal Dutta, Ramani Kanta Thakuria and Kakali Konwar. 2019. Correlation Studies and Predictive Models of Kharif Greengram based on Agroclimatic Indices. Int.J.Curr.Microbiol.App.Sci. 8(11): 606-612.

doi: https://doi.org/10.20546/ijcmas.2019.811.074 